\title{
Technology to Increase Hydrocarbon Wear Resistance of Friction Units of Hydrogen Aggregates
}

\author{
Mikhail Shalygin ${ }^{1 *}$ and Sergei Kuznetsov ${ }^{2}$ \\ ${ }^{1}$ Bryansk State Technical University, Department of Pipeline Transport Systems, 241035 Bryansk, 7, \\ Boulevard of 50 years of October, The Russian Federation \\ ${ }^{2}$ Bryansk State University, Department of Chemistry, 241000 Bryansk, 28 Bezhitskaya st., The \\ Russian Federation
}

\begin{abstract}
The causes of hydrogen wear of the friction surfaces involved in hydrocarbon transfer and distillation processes are considered. Some technological methods for reducing the hydrogen wear of parts and friction units operating in hydrocarbon environment are given. A comprehensive technology for obtaining the properties of the surface layer is proposed, which provides an increase in the wear resistance of a friction pair and smoothing the surface roughness. The increase in wear resistance is based on several mechanisms: (1) decreasing biographical hydrogen due to the dehydration process; (2) smoothing surface irregularities by saturating the surface with silicon; (3) reducing the diffusion capacity of the steel surface caused by diffusion siliconizing; (4) reducing grain size of the material. Comparative wear tests were carried out, which showed the effectiveness of the proposed methods.
\end{abstract}

\section{Introduction}

Hydrogen has the smallest size of an atom among all the chemical elements. In the process of transporting hydrocarbon raw material (oil, gas and others) there is an intense wear of the friction surfaces which are in contact with the hydrocarbon environment. Pumping and compressor installations are subject to hydrogen wear due to diffusing atomic hydrogen released from the environment into the surface layers of the material. Part of atomic hydrogen is adsorbed on the surface, but most of it under the action of the pressure gradient and temperature penetrates deep into the material where it has molecule formation from ions and causes excessive pressures in the lattice defects, which in turn contributes to more intense wear of the friction pair. Hydrogen (biographical) formed in the material during its manufacture (casting, machining) under the influence of the temperature gradient also tends to the friction zone. In the oil and gas industry hydrogen wear is one of the main reasons for destructing friction pairs. In the oil and gas industry, hydrogen wear is one of the main causes of destructing friction pairs. From the study [1] it was concluded that the components of the throttle used in the oil and gas field were damaged by corrosion and

\footnotetext{
* Corresponding author: Migshalygin@yandex.ru
} 
hydrogen. In the study [2], WS2 nanoparticles were used as an effective additive candidate, preventing the penetration of hydrogen into the rolling nodes at high temperatures and pressures. The modified WS2 oil reduced the concentration of penetrated hydrogen in bearing steel and led to the controlled wear and smoother tracks. However, the applicability of this technique for sliding friction pairs is not given. The conducted studies [3] show that hydrogen also adversely affects the durability of polymers. The authors carried out experimental studies on tests for polymer wear in hydrogen environment under high pressure. It is shown that hydrogen leads to increasing the rate of polymer wear, for example, nitrile butadiene rubber, as an example of an elastomer plastic, and, therefore, can contribute to the wear of the sealing elements of oil pumping units. Some methods of improving hydrogen wear resistance are given in [4]. During the friction of two contacting surfaces, which were iron-carbon steels and polyethylene oxide (PEO) layers synthesized on the AMG-6 alloy, a spinel-type film (hercynite) was formed. This film was a reliable protection against the surface wear exposed to hydrogen. Another method is given in [5]. A new instrument, called TriDes, was created, based on the phenomenon of mechanically stimulated gas emission, which allows determining the mechanical properties and hydrogen concentration, with a high spatial resolution. Its applicability to developing high-strength tubular steel, as well as the types of steel used in the marine environment was investigated. The hydrogen absorption analysis, accompanied by corroding high-strength low-alloy steel, showed a significant increase in hydrogen concentration. Hydrogen had a high mobility in steel, despite the presence of barriers - dispersed carbides.

Studies show that effective decrease of hydrogen wear requires a set of measures aimed at reducing the concentration of biographical hydrogen in a material, reducing the diffusing capability of a material or reducing the diffusing ability of hydrogen and reducing active centers on the material surface [6,7]. As such measures, the processes of grain and phase formation in the material, material dehydration and technological methods of hardening the surface layer are proposed.

At present, various combined and complex processing methods are widely used for surface hardening. One of the effective methods of influencing the surface layer is diffusion siliconizing. A diffusion siliconized layer on carbon steel is formed as a result of interacting silicon tetrachloride vapors with metal at temperatures of $990-1100^{\circ} \mathrm{C}$ [8]. By itself, diffusion siliconizing is used to increase the surface resistance against corrosion in a gaseous environment and does not lead to any improvement in the surface wear-resistant properties. For this reason, to increase technologically the wear resistance of friction surfaces, complex processing is required. Responsible surfaces of steel parts are subjected to various types of treatments, in order to give them the required physical and mechanical properties, when working in hydrogen-containing environments. The problem of hydrogen wear of friction surfaces is acute in the nodes operating in aggressive, hydrogen-containing environments, which include hydrocarbons.

In [9], a comprehensive treatment of friction surfaces of steel parts was proposed, which increases the wear resistance of critical friction sites subjected to hydrogen wear, including: heat treatment to reduce grain sizes; dehydration to reduce the concentration of biographical hydrogen in the sample, ion implantation with silicon to reduce the diffusion of hydrogen from the lubricant or hydrogen-containing environment. In [10], it was proposed, as a measure to reduce the wear of parts operating in hydrogen-containing environments, diffusion siliconizing of friction surfaces. In [11], it was noted that diffusion siliconizing from high-molecular-weight organic silicon compounds using laser processing ensured formating on the surface of steel molds uniform defect-free layers consisting of higher iron silicides and $\alpha$-phase with microhardness up to $114 \mathrm{MPa}$.

In this paper, a combination of methods is considered: heat treatment - mechanical treatment (machining) - dehydration - diffusion siliconizing, allowing controlling the 
characteristics of the surface layer quality and increasing the hydrogen wear resistance. The properties and microgeometry of the surface layer, the metallographic structure and the effect on the wear resistance of steel samples 40x13, strengthened by a complex of these methods, are studied.

\section{Processing technique}

Heat treatment of steel samples $40 \mathrm{X} 13$ was carried out in a furnace. Samples were quenched to a temperature of $955^{\circ} \mathrm{C}$, were aged at a temperature of $230^{\circ} \mathrm{C}$ for 1 hour, were cooled in water. Dewatering was carried out on the installation described in [12]. Before being placed in the chamber, the samples were washed with gasoline and carbon tetrachloride. After placing the samples in the installation chamber, the chamber was sealed and the air was pumped out of the chamber to the pressure of $1.8 \cdot 10^{-4} \mathrm{~Pa}$. When the vacuum of $1.8 \cdot 10^{-4} \mathrm{~Pa}$ was reached, the electric furnace was turned on and the chamber was heated to the temperature of $523 \mathrm{~K}$. The onset of hydrogen desorption from the samples was judged by the pressure drop in the chamber. When the vacuum reached $1.8 \cdot 10^{-4} \mathrm{~Pa}$ at the temperature of $523 \mathrm{~K}$ the electric furnace was turned off, and when the temperature in the chamber reached $293 \mathrm{~K}$, air was started into it.

Machining the samples was carried out on a grinding machine to the surface roughness of the samples $\mathrm{Ra}=0.2 ; 0.4 ; 1.6$ microns. Diffusion siliconizing was carried out in the chamber in which the temperature was maintained not exceeding $230^{\circ} \mathrm{C}$ to prevent phase transformations in steel. The sample was placed in the chamber completely coated with powdered silicon carbide. The sample was irradiated and kept in the chamber for 30 minutes, after which the chamber was opened and the sample was cooled in air.

\section{Results and discussion}

The study of the end surface after etching in nitric acid showed (fig. 1) that there was a lattice structure at the end. The location of the lattice structure relative to the sample surface was 40-600. The greatest depth of forming the structure did not exceed $4.2 \mathrm{~mm}$. The deeper the lattice structure was, the thinner its faces were and in some places, there was a gap. 


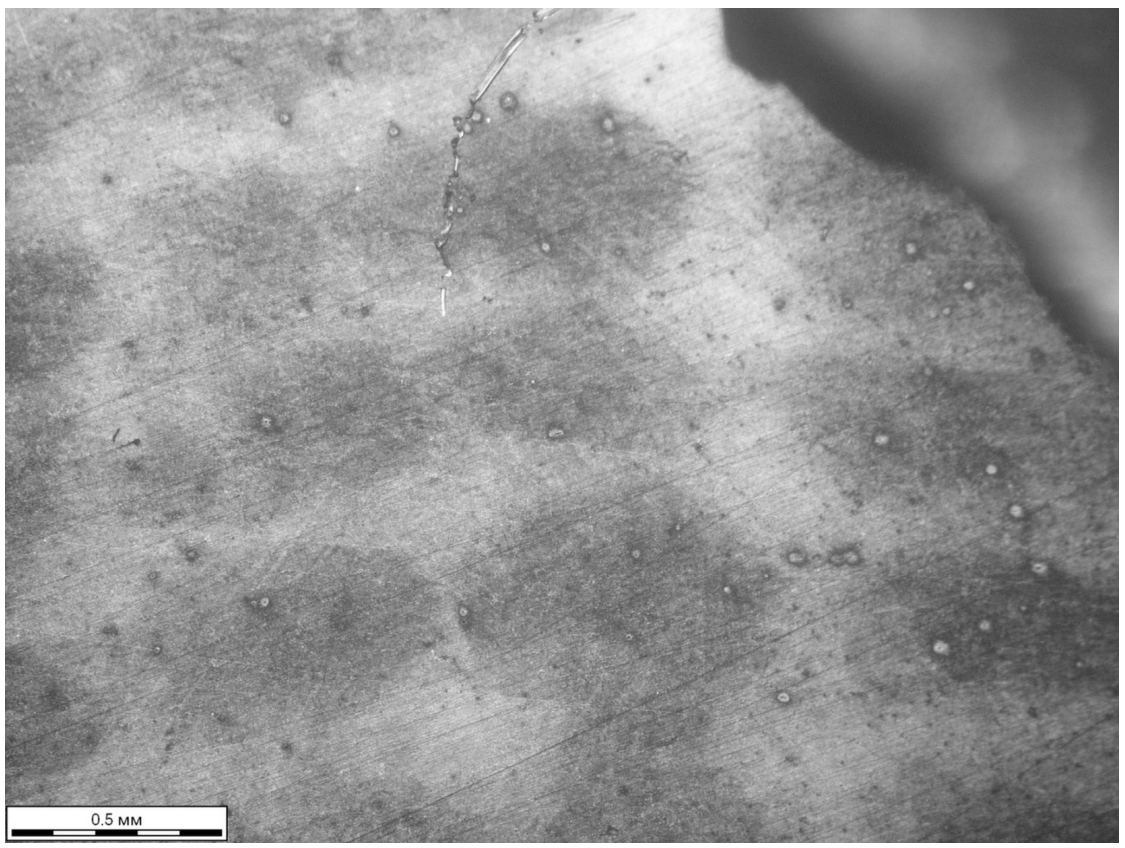

Fig. 1. The shear of the sample end surface.

The sample hardness decreased after the complex treatment from $44.5 \mathrm{HRC}$ after heat treatment (HT) to $42 \mathrm{HRC}(\mathrm{CT})$. The yield strength, compared with the heat-treated sample $\sigma_{\mathrm{y}}=770 \ldots 790 \mathrm{MPa}(\mathrm{HT})$, increased to $\sigma_{\mathrm{y}}=1300 \ldots 1320 \mathrm{MPa}(\mathrm{CT})$. The ultimate strength increased from $\sigma_{\mathrm{s}}=990 \ldots 1010 \mathrm{MPa}(\mathrm{HT})$ for heat-treated samples to $\sigma_{\mathrm{s}}=1620 \ldots 1640$ $\mathrm{MPa}(\mathrm{CT})$ for samples after carrying out complex processing.

The samples were tested for wear (fig. 2). Thermally treated steel 40x13, with hardness of $45 \ldots 47 \mathrm{HRC}$ and roughness identical to the tested sample was used as a counterbody. The load during the test was maintained at $\mathrm{P}=50 \mathrm{~N}$. Mass wear was measured every 1000 meters. For this path of friction, the sample performed 12.7 cycles.

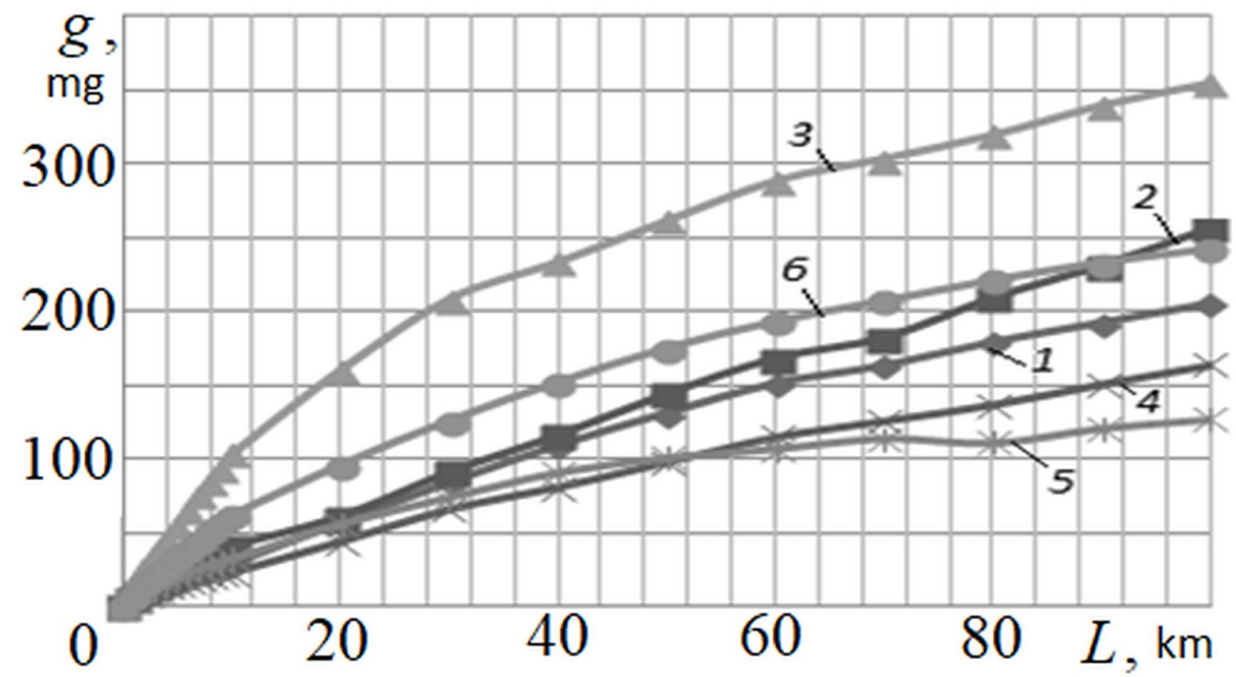


Fig. 2. The results of testing steel wear 40X13: thermal and mechanical processing: $(1-R a=0.2$ micron; $2-R a=0.4$ micron; $3-R a=1.6$ micron.); Complex treatment (CT) $(4-R a=0.2$ micron; $5-R a=0.4$ micron; $6-R a=1.6$ micron)

Measuring the surface roughness of the samples after machining and diffusion siliconizing showed that the decrease in the roughness parameter $\mathrm{Ra}$ was insignificant, within the permissible error $(<1 \%)$. The roughness parameter $\mathrm{Sm}$ decreased on average by 2.5 times, which makes it possible to assert that the roughness of the surface layer was smoothed.

\section{Conclusions}

Completed studies of complex processing consisting of thermal and mechanical treatments, dehydration and diffusion siliconizing show the possibility of forming surface microgeometry and changing the physical and mechanical properties aimed at ensuring the quality and durability of the surface layer of friction units operating in hydrogen-containing environment. Introducing complex processing will allow several times reducing the wear of machine and mechanism friction units operating in hydrogen-containing environment.

The effectiveness of CT technology is to reduce grain size by heat treatment, to reduce the biographical hydrogen concentration in a material by dehydrating, to increase penetration resistance into the surface layer of operational hydrogen and to fill material defects using diffusion siliconizing method, smoothing the surface sub-roughness profile and changes in the material structure. Complex processing consisting of thermal and mechanical treatment, dehydration and diffusion siliconizing shows the possibility of forming surface microgeometry and changing the physicomechanical properties aimed at ensuring the quality and durability of the surface layer of friction units operating in hydrogen-containing environments.

\section{References}

1. H.M.Tawancy, Luai M. Alhems, Case Studies in Engineering Failure Analysis, 7, 56 (2016)

2. V. Bogdan N. Hiroyoshi Tanaka, WS2 nanoadditized lubricant for applications affected by hydrogen embrittlement, 5, 40678 (2015)

3. E. R. Duranty, T. J. Roosendaal, S. G. Pitman, J. C. Tucker, S. L. Owsley, J. D. Suter, and K. J. Alvinea, Review of Scientific Instruments, 88, 095114 (2017)

4. V. Hutsaylyuk, M. Student, V. Dovhunyk, V. Posuvailo, O. Student, P. Maruschak and I. Koval'chuck, Plasma Electrolytic Oxidation Layers Synthesized on Aluminum Alloys. Metals, 9:3, 280, (2019)

5. R. Nevshupa, E. Grinkevych, K.E., Martinez, Materiales de Construcción, 66, 324 (2016)

6. A. G. Suslov, M. G. Shalygin, Proceedings of the Institution of Mechanical Engineers, Part J: Journal of Engineering Tribology (2019)

7. O.A. Gorlenko, M.G. Shalygin, G.N. Makarov, Russian Engineering Research, 38:7, 499 (2018)

8. S. Asgary, M.R. Hantehzadeh, M. Ghoranneviss, M. Phys. Metals Metallogr, 118, 1127 (2017)

9. M.G. Shalygin, Science intensive technologies in mechanical engineering, 7, 10 (2016)

10. K.V. Chizh, L.V. Arapkina, D.B. Stavrovsky, P.I. Gaiduk, V.A. Yuryev, Materials Science in Semiconductor Processing, 99, 78 (2019) 
11. R. Fang, R. Li, Z. Wang, Ch. Miao, W. Xiao, Y. Zhang, X. Yan, Yu. Jiang, C composite anodes from low-cost and industrial AlSiFe alloy powders. Solid State Ionics, 337, 42 (2019)

12. M.G. Shalygin, Construction and road machinery, 9, 51 (2018) 